\title{
PROBLEM OF HEART SALVATION DURING REPERFUSION. OPIOID RECEPTOR AGONISTS AS A POSSIBLE SOLUTION
}

\author{
IGOR KHALIULIN', LEONID N. MASLOV ${ }^{2}$ \\ 'School of Clinical Sciences, University of Bristol, Bristol, UK \\ ${ }^{2}$ Cardiology Research Institute, Tomsk National Research Medical Centre, Tomsk, Russia
}

\begin{abstract}
Ischaemia/reperfusion cardiac injury contributes to morbidity and mortality during percutaneous coronary intervention, heart surgery and transplantation. Even when the recanalization of an infarct-related coronary artery is carried out successfully, there is still a risk of death due to reperfusion injury. Numerous pharmacological interventions have been found in experiments on animals. However, the translation of these interventions to clinical practice has been disappointing. None of the drug treatment has been able to improve in-hospital mortality of patients with acute myocardial infarction. The search for pharmacological agents able to salvage myocardium during reperfusion continues. Opioid receptor (OR) agonists represent one of the promising group of drugs for treatment of patients with myocardial infarction. It has been found that $\mu$-, $\delta$ - and $\mathrm{k}-\mathrm{OR}$ agonists are able to attenuate heart injury when administered before or at the beginning of reperfusion. However, what kind of OR receptors need to be activated in order to protect the heart during reperfusion and the precise mechanism of this effect have yet to be elucidated.
\end{abstract}

Key words: ischemia/reperfusion injury, heart, myocardial infarction, cardioprotection, opioid receptor agonists.

The attempts to salvage myocardium during reperfusion using pharmacological interventions

It is commonly accepted that the only effective treatment of myocardial infarction is recanalization of the infarct-related coronary artery. This can be achieved by thrombolysis, percutaneous coronary intervention (PCI), or coronary artery bypass grafting [1-3]. Unfortunately, there is always a risk of death for patients with myocardial infarction, even when the recanalization of the coronary artery is carried out fast and successfully [4]. Therefore, there is a pressing need for creation of new generation drugs able to prevent reperfusion heart injury.

Nowadays, no drug is available, which would be able to attenuate effectively the area of necrosis and mortality in patients with acute myocardial infarction. Different pharmaceutical companies and scientific laboratories carry out the search for this kind of medicine. However, until now, no breakthrough has been achieved in this area.

A number of drugs have been clinically tested for reperfusion injury. For example, it has been proposed that the calcium sensitizer levosimendan has a potential to reduce infarct size. The randomized double-blind clinical study showed improvement of hemodynamic function in patients with ST-elevation myocardial infarction (STEMI) treated by PCI. However, no infarct-limiting effect of levosimendan was found [5]. Inhibitors of $\mathrm{Na}+\mathrm{H}+$ exchanger that showed cardioprotective properties in animal models [6] failed to protect heart in clinical settings [7] and even demonstrated increased mortality [8]. The gold standard MPTP inhibitor cyclosporine $\mathrm{A}$, which showed infarctlimiting effect in laboratory experiments [9-11], did not reduce the risk of the composite outcome of death from any cause, worsening of heart failure during the initial hospitalization/rehospitalization, or causing adverse left ventricular remodelling in patients with STEMI [12]. The P2Y12 receptor inhibitor clopidogrel appeared to reduce infarct size in patients with acute myocardial ischemia $[13,14]$, but had no effect on mortality in patients with this kind of pathology [15]. A statin atorvastatin neither improved left ventricular function, nor reduced infarct size in STEMI patients [16-18]. Intravenous adenosine infusion has been found to reduce infarct size and attenuate the No Reflow phenomenon in STEMI patients [19-22]. However, as Cohen M.V. and Downey J.M. [23] have pointed out, the ability of adenosine administered at or shortly before reperfusion to provide cardioprotection against infarction is indeed quite controversial. The authors noted that cardioprotective effect of the intravenous infusion of adenosine occurred when it was used as a form of preconditioning, prior to ischemia, 
whilst given at reperfusion, adenosine simply did not protect the heart. The infarct-limiting effect of a piperazine derivative trimetazidine is also debatable $[24,25]$. In general, the drugs mentioned above showed cardioprotective effects in experiments on animal models or in patients when administered prior to recanalization of the infarct-related coronary artery, but were ineffective in clinical settings when introduced during reperfusion. Furthermore, none of these medicines could improve in-hospital mortality of patients with STEMI.

Clinical relevance of the use of a cardioprotective agent prior to ischemia is restricted to cardiac surgery, when ischemia is caused by aortic crossclamping. However, in most cases, it is impossible to predict an incident of acute myocardial ischemia and carry out the treatment prior to the ischemic event. A possibility to attenuate specifically the reperfusion heart injury had been unclear until the discovery of the phenomenon of ischemic postconditioning in 2003 [26]. The authors demonstrated that a few brief (30 sec each) episodes of ischemia and reperfusion produced at the commencement of reperfusion following prolonged ischemia halved infarct size. Based on these data, many scientist are trying to find the way to salvage the myocardium during reperfusion by treating the heart not before ischemia, but just before or during reperfusion. In this context, opioid receptor $(\mathrm{OR})$ agonists represent a promising group of drugs.

\section{Opioid receptors as novel targets for prevention of reperfusion heart injury}

It has been shown [27-29] that OR agonists reduce infarct size when administered before the onset of reperfusion. Thus in 2004, Gross E.R. et al. [29] found that intravenous infusion of a preferential $\mu$-OR morphine or $\delta$-OR agonist BW373U86 $(1 \mathrm{mg} / \mathrm{kg}) 5 \mathrm{~min}$ prior to reperfusion in rats promotes decrease in infarct size-to-area at risk ratio (IS/AAR). These results are consistent with a recent study indicating that the selective $\mu$-OR agonist endomorphine-1 $(50 \mu \mathrm{g} / \mathrm{kg})$ reduced infarct size when injected intravenously $5 \mathrm{~min}$ before reperfusion [30]. Infarct-limiting effect of morphine during reperfusion has also been confirmed by Gong et al. [27]. Intravenous injection of the selective к1-OR agonist U-50,488 $(0.1 \mathrm{mg} / \mathrm{kg}) 5 \mathrm{~min}$ before reperfusion reduced IS/AAR [28]. This effect was abolished by the inhibition of $\kappa 1-O R$ with nor- binaltorphimine.

The precise mechanism of the cardioprotective effect of the $\mathrm{OR}$ agonists during reperfusion has yet to be discovered. However, it has been established that ORs represent $\mathrm{Gi} / \mathrm{o}$-coupled receptors that inhibit adenylyl cyclase and activate phospholipase $\mathrm{C}$, which in turn, synthesizes diacylglycerols stimulating protein kinase $\mathrm{C}$ (PKC) [31]. This was confirmed by the work of Peart J.N. \& Gross G.J. They showed in the experiments on isolated perfused murine heart that pertussis toxin, which rybosylates the ai subunit of the Gi/o protein, eliminated the cardioprotective effect of morphine [32]. Currently it is suggested that $\mathrm{Gi} / \mathrm{o}$ proteins serve as an intermediary link between ORs and the protein kinases that perform the protective signaling [33]. The following kinases may be involved in the cardioprotective mechanism of the ORs/ Gi/o activation: PKC [32, 33]; PI3 kinase, Akt, and MAPK - the RISK pathway [34, 35]; GSK-3 $\beta$ and JAK2 [36]. The endothelial nitric oxide synthase (eNOS) has been implicated in the preconditioning-induced triggering of Gi/o coupled receptors/PKC pathway [37] and could be involved in the protective effect of ORs [38]. Redox signaling has also been found to participate in the effects of ORs [39]. The studies have also indicated that these effects of OR agonists result in inhibition of mitochondrial permeability transition pore opening [33], which are critical in reperfusion-induced heart injury [40].

Taken together, it is of paramount importance to find a pharmacological intervention able to salvage myocardium during reperfusion and OR agonist represent a perspective group of drugs in this respect. Further studies are needed in order to establish what kind of ORs need to be activated to achieve the optimal heart salvation during reperfusion and the mechanism involved.

\section{REFERENCES}

1. P.W. Serruys, M.-C. Morice, A.P. Kappetein, A. Colombo, D.R. Holmes, M.J. Mack et al. Percutaneous Coronary Intervention versus Coronary-Artery Bypass Grafting for Severe Coronary Artery Disease. N Engl J Med. 2009; 360(10): 961-972.

2. D. Joyal, J. Afilalo, S. Rinfret Effectiveness of recanalization of chronic total occlusions: A systematic review and meta-analysis. Am Heart J. 2010; 160(1): 179-187. 
3. Ito H., Okamura A., Iwakura K., Masuyama T., Hori M., Takiuchi S. et al. Myocardial Perfusion Patterns Related to Thrombolysis in Myocardial Infarction Perfusion Grades After Coronary Angioplasty in Patients With Acute Anterior Wall Myocardial Infarction. Circulation. 1996; 93(11): 1993-9.

4. S.S. Rathore, J.P. Curtis, J. Chen, Y. Wang, B.K. Nallamothu, A.J. Epstein, H.M. Krumholz R. for the National Cardiovascular Data, Association of door-to-balloon time and mortality in patients admitted to hospital with ST elevation myocardial infarction: national cohort study. BMJ. 2009; 338: b1807.

5. T. Husebye, J. Eritsland, C. Müller, L. Sandvik, H. Arnesen, I. Seljeflot, A. Mangschau, R. Bjørnerheim, G.Ø. Andersen, Levosimendan in acute heart failure following primary percutaneous coronary intervention-treated acute ST-elevation myocardial infarction. Results from the LEAF trial: a randomized, placebo-controlled study. Eur J Heart Fail. 2013; 15(5): 565-572.

6. T. Toda, T. Kadono, M. Hoshiai, Y. Eguchi, S. Nakazawa, H. Nakazawa, N. Higashijima, H. Ishida $\mathrm{Na}+/ \mathrm{H}+$ exchanger inhibitor cariporide attenuates the mitochondrial $\mathrm{Ca} 2+$ overload and PTP opening. Am J Physiol Heart Circ Physiol. 2007; 293(6): H3517.

7. Zeymer U., Suryapranata H., Monassier J.P., Opolski G., Davies J., Rasmanis G. et al. The $\mathrm{Na}+/$ $\mathrm{H}+$ exchange inhibitor eniporide as an adjunct to early reperfusion therapy for acute myocardial infarction1: Results of the evaluation of the safety and cardioprotective effects of eniporide in acute myocardial infarction (ESCAMI) trial. J Am Coll Cardiol. 2001; 38(6): E1644-E1650. https://doi. org/10.1016/S0735-1097(01)01608-4

8. R.M. Mentzer, Jr. C. Bartels, R. Bolli, S. Boyce, G.D. Buckberg, B. Chaitman et al. SodiumHydrogen Exchange Inhibition by Cariporide to Reduce the Risk of Ischemic Cardiac Events in Patients Undergoing Coronary Artery Bypass Grafting: Results of the EXPEDITION Study. Ann Thorac Surg. 2008; 85(4): 1261-1270.

9. L.F. González Arbeláez, A. Ciocci Pardo, J.C. Fantinelli, S.M. Mosca, Cyclosporine-A mimicked the ischemic pre- and postconditioning-mediated cardioprotection in hypertensive rats: Role of PKC $\varepsilon$. Exp Mol Pathol. 2016; 100(2): 266-275.

10. N. Wu, W.N. Li, W.Q. Shu, Y. Lv, D.L. Jia Blocking the mitochondrial permeability transition pore with cyclosporine-A can restore cardioprotection of ischemic postconditioning in hypercholesterolemic rat heart. Eur Rev Med Pharmacol Sci. 2015; 19(3): 446-54.

11. E.J. Griffiths, A.P. Halestrap Protection by Cyclosporin A of ischemia/reperfusion-induced damage in isolated rat hearts. J Mol Cell Cardiol. 1993; 25(12): 1461-9.

12. T.-T. Cung, O. Morel, G. Cayla, G. Rioufol, D. Garcia-Dorado, D. Angoulvant et al. Cyclosporine before PCI in Patients with Acute Myocardial Infarction. New Eng J Med. 2015; 373(11):10211031. DOI: 10.1056/NEJMoa1505489

13. Roubille F., Lairez O., Mewton N., Rioufol G., Ranc S., Sanchez I. et al. Cardioprotection by clopidogrel in acute ST-elevated myocardial infarction patients: a retrospective analysis. Basic Res Cardiol. 2012; 107(4): 275. doi: 10.1007/ s00395-012-0275-3. Epub 2012 Jun 21.

14. Song Y.B., Hahn J.Y., Gwon H.C., Chang S.A., Lee S.C., Choe Y.H. et al. A high loading dose of clopidogrel reduces myocardial infarct size in patients undergoing primary percutaneous coronary intervention: A magnetic resonance imaging study. Am Heart J. 2012 Mar;163(3):500-7. doi: 10.1016/j. ahj.2011.12.007.

15. Bellemain-Appaix A., O’Connor S.A., Silvain $\mathrm{J}$., et al. Association of clopidogrel pretreatment with mortality, cardiovascular events, and major bleeding among patients undergoing percutaneous coronary intervention: A systematic review and meta-analysis. JAMA. 2012; 308(23): 2507-2516.

16. Hahn J.Y., Kim H.J., Choi Y.J., Jo S.H., Kim H.J., Lee S. et al. Effects of atorvastatin pretreatment on infarct size in patients with STsegment elevation myocardial infarction undergoing primary percutaneous coronary intervention.Am Heart J. 2011; 162(6): 1026-33. doi: 10.1016/j. ahj.2011.08.011

17. Kim E.K., Hahn J.-Y., Song Y.B., Chang S.-A., Choi J.-H., Choi S.-H. et al. Effects of High-dose Atorvastatin Pretreatment in Patients with ST-segment Elevation Myocardial Infarction Undergoing Primary Percutaneous Coronary Intervention: A Cardiac Magnetic Resonance Study. J Korean Med Sci. 2015; 30(4): 435-441. doi: 10.3346/jkms.2015.30.4.435

18. PostS. , Post M.C., van den Branden B.J., Eefting F.D., Goumans M.-J., Stella P.R. et al. Early statin treatment prior to primary PCI for acute myocardial infarction: REPERATOR, a randomized 
placebo-controlled pilot trial. Catheter Cardiovasc Interv. 2012; 80(5): 756-765.

19. Mahaffey K.W., Puma J.A., Barbagelata N.A., DiCarli M.F., Leesar M.A., Browne K.F. et al. Adenosine as an adjunct to thrombolytic therapy for acute myocardial infarction: Results of a multicenter, randomized, placebo-controlled trial: the Acute Myocardial Infarction STudy of ADenosine (AMISTAD) Trial. J Am Coll Cardiol. 1999; 34(6): 1711-1720.

20. Micari A., Belcik T.A., Balcells E.A., Powers E., Wei K., Kaul S., Lindner J.R. Improvement in microvascular reflow and reduction of infarct size with adenosine in patients undergoing primary coronary stenting. Am J Cardiol. 2005; 96(10):1410-1415.

21. A.M. Ross, R.J. Gibbons, G.W. Stone, R.A. Kloner, R.W. Alexander A Randomized, Double-Blinded, Placebo-Controlled Multicenter Trial of Adenosine as an Adjunct to Reperfusion in the Treatment of Acute Myocardial Infarction (AMISTAD-II). J Am Coll Cardiol. 2005; 45(11): 1775-1780. doi: https://doi.org/10.1016/j. jacc.2005.02.061.

22. Wang J., Chen Y.-D., Zhi,G. XuY., Chen,L., Liu H.-B. et al. Beneficial effect of adenosine on myocardial perfusion in patients treated with primary percutaneous coronary intervention for acute myocardial infarction.Clin Exp Pharmacol Physiol. 2012; 39(3): 247-252.

23. Cohen M.V., Downey J.M. AMISTAD Trials: Possible Reasons for Lack of Success. Journal of the American College of Cardiology. 2006; 47(6): 1236.

24. Di Pasquale P., Lo Verso P., Bucca V., Cannizzaro S., Scalzo S., Maringhini G. et al. Effects of Trimetazidine Administration before Thrombolysis in Patients with Anterior Myocardial Infarction: Short-term and Long-term Results. Cardiovasc Drugs Ther. 1999; 13(5): 423-428.

25. Steg P.G., Grollier G., Gallay P., Morice M.C., Karrillon G.J., Benamer H. et al. A randomized double-blind trial of intravenous trimetazidine as adjunctive therapy to primary angioplasty for acute myocardial infarction. Int J Cardiol. 2001; 77(2-3): 263-273.

26. Zhao Z.-Q., Corvera J.S., Halkos M.E., Kerendi F., Wang N.-P., Guyton R.A., VintenJohansen J. Inhibition of myocardial injury by ischemic postconditioning during reperfusion: comparison with ischemic preconditioning. Am J Physiol Heart Circ Physiol. 2003; 285(2): H579.

27. Gong Z.X., Ran K., Chang Y.T., Xu J.M.
Effect of morphine postconditioning on myocardial ischemia-reperfusion injury in rabbits. Zhejiang Da Xue Xue Bao Yi Xue Ban. 2009; 38(5): 521-4.

28. Zhang W.P., Zong Q.F., Gao Q., Yu Y., Gu X.Y., Wang Y., Li Z.H., Ge M. Effects of endomorphin-1 postconditioning on myocardial ischemia/reperfusion injury and myocardial cell apoptosis in a rat model. Mol Med Rep. 2016; 14(4): 3992-8.

29. Gross E.R., Hsu A.K., Gross G.J. OpioidInduced Cardioprotection Occurs via Glycogen Synthase Kinase $\beta$ Inhibition During Reperfusion in Intact Rat Hearts. Circ Res. 2004; 94(7): 960.

30. Maslov L.N., Khaliulin I., Zhang Y., Krylatov A.V., Naryzhnaya N.V., Mechoulam R. et al. Prospects for creation of cardioprotective drugs based on cannabinoid receptor agonists. J Cardiovasc Pharmacol Ther. 2016; 21(3): 262-272.

31. Dhawan B.N., Cesselin F., Raghubir R., Reisine T., Bradley P.B., Portoghese P.S., Hamon M. International Union of Pharmacology. XII. Classification of opioid receptors. Pharmacol Rev. 1996; 48(4): 567.

32. Peart J.N., Gross G.J. Cardioprotective effects of acute and chronic opioid treatment are mediated via different signaling pathways. Am J Physiol Heart Circ Physiol. 2006; 291(4): H1746.

33. Maslov L.N., Khaliulin I., Oeltgen P.R., Naryzhnaya N.V., Pei J.M., Brown S.A. et al. Prospects for creation of cardioprotective and antiarrhythmic drugs based on opioid receptor agonists. Med Res Rev. 2016; 36(5): 871-923.

34. Fryer R.M., Patel H.H., Hsu A.K., Gross G.J. Stress-activated protein kinase phosphorylation during cardioprotection in the ischemic myocardium. Am J Physiol Heart Circ Physiol. 2001; 281(3): H1184.

35. Xu J., Tian,W. Ma X., Guo J., Shi Q., Jin Y. et al. The Molecular Mechanism Underlying Morphine-Induced Akt Activation: Roles of protein phosphatases and reactive oxygen species. Cell Biochem Biophys. 2011; 61(2): 303-311.

36. Gross E.R., Hsu A.K., Gross G.J. The JAK/ STAT pathway is essential for opioid-induced cardioprotection: JAK2 as a mediator of STAT3, Akt, and GSK-3 $\beta$. Am J Physiol Heart Circ Physiol. 2006; 291(2): H827.

37. Cohen M.V., Downey J.M. Signalling pathways and mechanisms of protection in pre- and postconditioning: historical perspective and lessons for the future. Br J Pharmacol. 2015; 172(8): 1913- 
1932.

38. Wu X., Zhang B., Fan R., Zhao L., Wang Y., Zhang S. et al. U50,488H inhibits neutrophil accumulation and TNF- $\alpha$ induction induced by ischemia-reperfusion in rat heart. Cytokine. 2011; 56(2): 503-507.

39. Peart J.N., Gross G.J. Adenosine and opioid receptor-mediated cardioprotection in the rat: evidence for cross-talk between receptors. Am J Physiol Heart Circ Physiol. 2003; 285(1): H81.

40. Halestrap, Clarke A.P. S.J., Khaliulin I. The role of mitochondria in protection of the heart by preconditioning. Biochim Biophys Acta. 2007; 1767(8): 1007-1031.

Статья поступила 25.04.2017

For correspondence:

Khaliulin Igor

Address: 7 Bristol Royal Infirmary,

Upper Maudlin Street, Bristol, BS2 8HW, UK

Tel. +44 117 3422208,

E-mail: i.khaliulin@bristol.ac.uk 